\title{
Prevalence and correlates of non-daily and daily cannabis use among persons 15 years and older in South Africa: results of a national survey in 2017
}

\author{
Shandir Ramlagan ${ }^{1}$, Karl Peltzer ${ }^{1,2^{*}}$ (i) and Supa Pengpid ${ }^{2,3}$
}

\begin{abstract}
Background: The study aimed to assess the prevalence and correlates of non-daily and daily cannabis use among persons 15 years and older in South Africa.

Method: In a national cross-sectional 2017 survey, 39,207 persons 15 years and older (Median = 34 years) responded to a questionnaire on cannabis use and health variables. Multinominal logistic regression was used to assess the determinants of nondaily and daily cannabis use among the general population and logistic regression for the determinants of daily cannabis use among active cannabis users.

Results: Results indicate that $5.0 \%$ of the participants engaged in non-daily and $2.8 \%$ in daily cannabis use in the past 3 months. In adjusted multinomial logistic regression analysis, male sex, Grade 8-11 education, Coloureds, alcohol use disorder, never married, and other drug use were positively associated with daily cannabis use while not in not labour force was negatively associated with daily cannabis use. Moreover, male sex, never married, alcohol use disorder, and other drug use were positively, while physical multimorbidity was negatively associated with nondaily cannabis use. In adjusted logistic regression, compared to nondaily cannabis users, daily cannabis users were more likely male and were less likely not in the labour force and were less likely using other drugs.

Conclusion: About one in ten participants had used cannabis in the past 3 months in South Africa. Several sociodemographic and health indicators were identified that were associated with non-daily and/or daily cannabis use.
\end{abstract}

Keywords: Cannabis use, Alcohol use, Drug use, Adolescents, Adults, Health variables, South Africa

\section{Introduction}

Cannabis is the genus name of a plant from the Cannabaceae family [1] and cannabis is also the name associated with the drug produced from this plant [2]. Common names of cannabis in South Africa also include

\footnotetext{
* Correspondence: kfpeltzer@gmail.com

'Department of Human and Social Capabilities, Human Sciences Research Council, Private Bag X41, Pretoria 0001, South Africa

${ }^{2}$ Department of Research Administration and Development, University of Limpopo, Sovenga 0727, South Africa

Full list of author information is available at the end of the article
}

dagga, zol [3] and marijuana [4]. Globally, cannabis is the most commonly used drug [5]. The World Drug Report states that from 2010 to 2016, the increase in cannabis use appears to have been greatest in Africa and Asia [5]. According to statistics from the United Nations Office on Drugs and Crime (UNODC), globally in 2018, the annual prevalence of cannabis use was 3.86\% [6].

In terms of cannabis usage in different countries around the world, the prevalence of past 12-month cannabis use in Australia was 6\% in 2012 [7] and the annual 
prevalence in 2016 was $10.4 \%$ [2]. Annual prevalence of cannabis use in the United States of America was 18.4\% in 2017, $14.03 \%$ in New Zealand in 2017, 9.3\% in Uruguay in 2014, 2.5\% in Brazil in 2016 and 3.3\% in Bangladesh in 2004 [6] to state a few. In terms of UNODC cannabis statistics for South Africa, the organisation reports an annual cannabis prevalence at 3.65\% in 2011 , and that $43.3 \%$ of people in treatment facilities in 2018 were admitted for cannabis use [6].

In terms of a national population-based South African study, a 2012 study on persons 15 years and older reported the prevalence of past 3-month cannabis use at 4.0\% [8]. More recent South African data on cannabis use can be found from treatment centre data that shows that cannabis is the most used drug in South African treatment facility cases in the second half of 2016 [9] and the first half of 2017 [10]. The treatment facility reports, although they are limited as they only record the number of patients seeking treatment and the substances they are seeking treatment for. There is a lack of more recent national population-based data on the prevalence and correlates of nondaily and daily cannabis use in South Africa.

Risk factors for cannabis use or cannabis use disorder include sociodemographic factors and health variables. Sociodemographic risk factors for cannabis use include male sex [7, 11-14], younger age $[7,11,13]$, divorced, separated, never married [15], unemployed, living without a partner, higher education, and lower education [11]. Health variable risk factors include other illicit drug use $[11,12]$, alcohol use disorder $[7,11,12,14]$, psychological distress [16, 17], having no chronic conditions [12] and less frequent primary health care utilization $[18,19]$.

Cannabis is not indigenous to southern Africa; it is the most common illicit substance used in South Africa; it is inexpensive; it is easy to produce with South Africa being a large producer of cannabis, and the law prohibiting possession is infrequently enforced [3]. In terms of law, South Africa followed international treaties making cannabis usage a criminal offense [4], with the Prevention and Treatment of Substance Abuse Act 70 of 2008 speaking to the National Drug Master Plan on supply, demand and harm reduction [20]. These laws focused more towards drug trafficking [4] and thus not towards the individual user.

Epidemiological population-based surveys are needed to target interventions to prevent harmful cannabis use. The study aimed to assess the prevalence and correlates of non-daily and daily cannabis use among persons 15 years and older in South Africa.

\section{Methods}

\section{Study design and participants}

A cross-sectional, nationally representative South African National HIV Prevalence, Incidence, Behaviour and
Communication Survey of persons 15 years and older in 2017 living in South Africa was analysed. This multistage stratified random cluster population-based household sample is described elsewhere [21]. In brief, the 2015 national population sampling frame [22] was utilized to draw 1000 small area layers (SALs) that were stratified by South Africas nine provinces, and locality types. In each of the 1000 SALs, 15 households were randomly selected to participate and all individuals living in the selected household that slept there the night before were invited to participate. It is important to point out that this paper utilized racial categorization where "Coloured" or mixed race is defined as children born to parents of Black African and either White and/or Indian/Asian race groups as per South Africa's Apartheid government's Act 30 of 1950. This is done to correct the inequalities of the previous apartheid regime.

\section{Study procedures}

Participants were handed an informed consent form to read together with a trained interviewer. If the participant agreed to participate, they signed the consent form. For those younger than 18 years old, parental consent was sought together with youth assent. If either the youth or the parent did not sign the assent/consent form, no interview was conducted. All interviews were done in private and kept confidential. Data were collected electronically on a tablet using CSPro software. Data collection started in December 2016 and ended in February 2018. The household response rate was $82.2 \%$ and the individual response rate to be interviewed was 93.6\% [21]. The participants did not receive any payment or gifts for the interview. For this paper, we restricted the sample to those with complete cannabis use measurement, $5.1 \%$ had missing cannabis values.

\section{Measures}

Non-daily and daily cannabis use was assessed using the question: "In the past three months, how often have you used cannabis (dagga, marijuana, pot, grass, hash, etc.)?" from the "Alcohol, Smoking and Substance Involvement Screening Test (ASSIST)" [23]. Response options were "Never, once or twice, monthly, weekly, or almost daily." "Non-daily" was defined as "once or twice, monthly, or weekly" and "almost daily" as "daily" cannabis use.

Past three months, other drug use was assessed with six items (cocaine, amphetamine, inhalants, sedatives, hallucinogens, and opiates) from the (ASSIST)" [23]. The six items were summed to define any other drug use in the past 3 months. Cronbach's alpha for the 6item other drug use measure was 0.97 in this sample.

Alcohol use disorder was assessed using the Alcohol Use Disorders Identification Test (AUDIT) [24] and was scored as in a previous survey in South Africa [25]. 
Among adults (20 years and above), a cut-off score of 8 or more [24] and among adolescents (15-19 years), 5 or more [26] for classifying an alcohol use disorder. (Cronbach alpha 0.87 in this sample).

Sociodemographic factors included age (15-29, 30-44, and 45 or more years), sex (male, female), highest educational level (pre-school or Gr R, grades 1-12, further studies incomplete, diploma/undergraduate degree/post school completed, further degree completed), marital status (married, never married, divorced or separated, widow or widower), population group or ethnicity (African, White, Coloured, Indian or Asian, other), employment status (unemployed, sick or disabled and unable to work, student or pupil or learner, employed of selfemployed, other) and residence status (rural informal or tribal areas, rural farms, urban) [21].

Psychological distress was assessed with the Kessler Psychological Distress Scale (K10), with scores 20 or more indicating psychological distress [27]. Cronbach's alpha for the K10 was 0.92 in this sample.

Physical multimorbidity was assessed with selfreported health care provider diagnosed hypertension, diabetes, HIV, cancer and heart disease (Yes, No).

Health care utilization was sourced from the question: When was the last time you went to see a health professional (doctor, nurse, traditional healer, etc.)? Response options were $1=$ within the last 6 months, $2=$ more than 6 months but not more than a year ago, $3=$ more than 1 year ago, and $4=$ never (coded $1=$ within the last 6 months and $0=2-4$ ).

\section{Data analysis}

All statistical analyses were conducted using STATA software version 14.0 (Stata Corporation, College Station, TX, USA). The data were weighted to make the sample representative of the target population in South Africa. Descriptive statistics were used to summarize the sample and cannabis use prevalence characteristics. Unadjusted and adjusted (including variables significant at $p<0.05$ in univariate analysis) multinomial logistic regression was used to predict nondaily and daily cannabis use, with no past 3-month cannabis use as the reference category. In addition, unadjusted and adjusted (including variables significant at $p<0.05$ in univariate analysis) logistic regression was used among active (past 3 months) cannabis users to predict daily versus nondaily cannabis use. Taylor linearization methods were applied to account for the complex study design and the sampling weight. Results from multinomial logistic regression analyses are reported as relative risk ratios and from logistic regression as odds ratios (ORs), and 95\% confidence intervals (CIs). Missing values $(<1.8 \%$ for any study variable) were excluded and $p<0.05$ considered significant.

\section{Results}

\section{Characteristics of the sample and cannabis use}

The sample comprised 39,207 persons 15 years and older $($ Median $=34$ years, interquartile range $=25-48), 48.3 \%$ were men, and $51.7 \%$ were women, $36.1 \%$ had Grade 12 or more education, $62.5 \%$ had never been married, and 79.3\% were Black African by population group or ethnicity. More than one in three participants (35.6\%) were employed or self-employed, $69.0 \%$ lived in urban areas, $20.5 \%$ reported psychological distress, $4.9 \%$ physical multimorbidity, and $47.3 \%$ past 6 -month health care utilization. More than one in ten respondents (10.3\%) had an alcohol use disorder, and $2.8 \%$ used drugs other than cannabis in the past 3 months. Five percent of the participants engaged in non-daily and $2.8 \%$ in daily cannabis use in the past 3 months (Table 1).

\section{Associations with non-daily and daily cannabis use among the general population}

In adjusted multinomial logistic regression analysis, male sex, Grade 8-11 education, Coloureds, alcohol use disorder, never married, and other drug use were positively associated with daily cannabis use while not in not labour force was negatively associated with daily cannabis use. Male sex, never married, alcohol use disorder, and other drug use were positively, while physical multimorbidity was negatively associated with nondaily cannabis use. In addition, in univariate multinomial logistic regression, urban residence was positively and Whites and Indians or Asians were negatively associated with daily cannabis use (Tables 2 and 3).

\section{Associations with daily cannabis use among active cannabis users}

In adjusted logistic regression, compared to nondaily cannabis users, daily cannabis users were more likely male and were less likely not in the labour force and were less likely using other drugs. In addition, in univariate analysis, grades $8-11$, urban residence, and alcohol use disorder were positively, and Whites and Indians or Asians and health care utilization were negatively associated with daily cannabis use (Table 4).

\section{Discussion}

This paper utilized data from a large national population-based household survey in 2017 to assess the prevalence and correlates of non-daily and daily cannabis use among persons 15 years and older living in South Africa. The study found that $5 \%$ of the participants engaged in non-daily and $2.8 \%$ in daily cannabis use in the past 3 months. This finding shows a considerable increase from previous studies where the prevalence of past 3 months cannabis use was found to be $4 \%$ [8] and $3.3 \%$ [4] during the 2012 and 2008 surveys which used 
Table 1 Sample characteristics and distribution of cannabis use among persons 15 years and older in South Africa, 2017

\begin{tabular}{|c|c|c|c|c|}
\hline \multirow[t]{3}{*}{ Variable } & \multirow{3}{*}{$\begin{array}{l}\text { Sample } \\
\text { N (\%) }\end{array}$} & \multicolumn{3}{|c|}{ Past 3-month cannabis use } \\
\hline & & Never $(N=36,503)$ & Non-daily $(N=1747)$ & Almost daily $(N=957)$ \\
\hline & & $\%$ & $\%$ & $\%$ \\
\hline All & 39,207 & 92.2 & 5.0 & 2.8 \\
\hline \multicolumn{5}{|l|}{ Sex } \\
\hline Female & $23,102(51.7)$ & 96.5 & 3.1 & 0.4 \\
\hline Male & $16,105(48.3)$ & 87.7 & 7.1 & 5.3 \\
\hline \multicolumn{5}{|l|}{ Age in years } \\
\hline $15-29$ & $15,524(38.1)$ & 90.5 & 6.3 & 3.3 \\
\hline $30-44$ & $10,604(32.4)$ & 91.6 & 5.2 & 3.3 \\
\hline 45 or more & $13,079(29.5)$ & 95.2 & 3.2 & 1.6 \\
\hline \multicolumn{5}{|l|}{ Education } \\
\hline Grade 0-7 & $16,887(37.3)$ & 93.6 & 4.6 & 1.8 \\
\hline Grade 8-11 & $9876(26.6)$ & 89.9 & 5.5 & 4.6 \\
\hline Grade 12 or more & $12,367(36.1)$ & 92.6 & 5.0 & 2.5 \\
\hline \multicolumn{5}{|l|}{ Marital status } \\
\hline Married & $10,514(28.9)$ & 95.6 & 3.1 & 1.3 \\
\hline Separated/divorced/widowed & $3739(8.6)$ & 96.0 & 2.7 & 1.3 \\
\hline Never married & $24,946(62.5)$ & 90.1 & 6.2 & 3.7 \\
\hline \multicolumn{5}{|l|}{ Population group } \\
\hline African Black & $30,670(79.3)$ & 92.3 & 4.9 & 2.8 \\
\hline White & $1924(9.0)$ & 93.7 & 4.8 & 1.4 \\
\hline Coloured & $4304(8.8)$ & 89.7 & 6.0 & 4.2 \\
\hline Indian or Asian & $2309(2.9)$ & 93.9 & 4.9 & 1.2 \\
\hline \multicolumn{5}{|l|}{ Employement status } \\
\hline Employed/self-employed & $11,937(35.6)$ & 91.9 & 4.7 & 3.4 \\
\hline Unemployed & $20,649(49.6)$ & 92.1 & 5.1 & 2.8 \\
\hline Not in labour force & $6571(14.8)$ & 93.4 & 5.4 & 1.2 \\
\hline \multicolumn{5}{|l|}{ Residence } \\
\hline Rural informal (tribal areas) & $13,584(26.0)$ & 93.4 & 4.8 & 1.8 \\
\hline Rural (farms) & $4266(5.0)$ & 92.3 & 5.2 & 2.5 \\
\hline Urban & $21,357(69.0)$ & 91.8 & 5.1 & 5.1 \\
\hline \multicolumn{5}{|l|}{ Alcohol use disorder } \\
\hline No & $36,067(89.7)$ & 93.8 & 4.2 & 2.0 \\
\hline Yes & $3087(10.3)$ & 78.3 & 11.9 & 9.8 \\
\hline \multicolumn{5}{|l|}{ Other drugs } \\
\hline No & $37,991(97.2)$ & 94.1 & 3.5 & 2.4 \\
\hline Yes & $1084(2.8)$ & 32.4 & 55.9 & 11.7 \\
\hline \multicolumn{5}{|l|}{ Psychological distress } \\
\hline No & $31,304(79.5)$ & 92.4 & 4.9 & 2.7 \\
\hline Yes & $7751(20.5)$ & 91.4 & 5.4 & 3.2 \\
\hline \multicolumn{5}{|l|}{ Physical multimorbidity } \\
\hline 0 & $29,394(77.2)$ & 91.3 & 5.5 & 3.2 \\
\hline 1 & 7056 (17.9) & 94.6 & 3.8 & 1.6 \\
\hline 2 or more & $2279(4.9)$ & 97.7 & 2.0 & 0.4 \\
\hline
\end{tabular}


Table 1 Sample characteristics and distribution of cannabis use among persons 15 years and older in South Africa, 2017 (Continued)

\begin{tabular}{|c|c|c|c|c|}
\hline \multirow[t]{3}{*}{ Variable } & \multirow{3}{*}{$\begin{array}{l}\text { Sample } \\
\text { N (\%) }\end{array}$} & \multicolumn{3}{|c|}{ Past 3-month cannabis use } \\
\hline & & Never $(N=36,503)$ & Non-daily $(N=1747)$ & Almost daily $(N=957)$ \\
\hline & & $\%$ & $\%$ & $\%$ \\
\hline \multicolumn{5}{|c|}{ Health care utilization } \\
\hline No & $20,823(52.7)$ & 90.8 & 5.7 & 3.6 \\
\hline Yes & $18,232(47.3)$ & 93.8 & 4.3 & 1.9 \\
\hline
\end{tabular}

the same survey methodology. During the same period as this survey, treatment study data showed that cannabis is the most used drug in South African treatment facility cases $[9,10]$.

The 2017 survey findings almost doubled that of the survey done in 2012 and could be attributed to the ease of access to cannabis and it being cost effective [3, 8]. It is also important to mention that previous studies have stated that laws on cannabis restrictions were in place during the survey period, but the enforcement of those laws were not geared to the single end user but rather to the drug trafficker $[3,4,20]$. Although cannabis use was illegal during the survey period, the medical benefits of cannabis [2] have been voiced and decriminalization propagated in South Africa [20]. All of this coupled together could potentially seem as although cannabis is more tolerated in South African society, thus leading to increased usage.

Evidence from this analysis shows that when compared to females, males were about 11 times more likely to be daily cannibis users. The finding that males are significantly associated with cannabis use concurs with previous published studies and South African treatment facility reports $[3,4,7,8,11-14,28,29]$. Although the data from our study is household data from the general population and does not ask for motivation for cannabis use, the treatment facility literature suggests that if more males are seeking treatment for their cannabis use than interventions are needed more especially for males.

Although those participants having Grade 8-11 education made up a quarter of the study population aged 15 years and older, this study found that they are positively associated with daily cannabis use. This finding is in contravention of the 2008 finding which showed that having a grade 8-11 educational level was protective for men [4] nor the 2012 finding which found no association between cannabis use and educational level [8]. This change from previous years is of concern as studies have shown that increasing cannabis use was associated with an increasing risk of leaving school without qualifications [30, 31]. These increases could be attributed to the ease with which cannabis can be obtained and law enforcements focus on drug traffickers rather than the end user [4]. Interestingly, persons not in the labour force had lower odds of daily cannabis use, which is a very promising outcome.
Respondents from the Coloured population group had significantly higher odds, of one and a half times, for daily cannabis use. This finding parallels previous cannabis and other drug studies [3, 4, 8, 32]. The coloured population could be experiencing increased stressors [33] which could account for the positive association. These stressors emanate from Apartheid era policies which marginalised non-white population groups in South Africa by limiting their access to better education, income generation, better living conditions, and so on. This generational impoverishment could have led to increased cannabis use and thus targeted interventions using an Intervention Mapping Framework [34] to find the most appropriate interventions are required to remedy the injustices of the past.

As found in previous research $[7,15]$, compared to individuals who never married, those who were married was found protective against cannabis use. It is possible that people who never married engage in daily cannabis use because of being disadvantaged in forming relationships [7] as this study found that they were two times more likely to be non-daily cannabis users and three times more likely to be daily cannabis users when compared to those who are married. The study showed that alcohol use disorder and other drug use were highly significantly positively associated with past 3-month daily and nondaily cannabis use, where those that used other drugs were 52 times more likely to be non-daily cannabis users and 16 times more likely to be daily cannabis users. These finds are similar to other research where it would seem that cannabis and alcohol usage are interlinked [7, 11, 12, 14, 35] as well as cannabis and other drug usage [11, 12]. Interestingly, the adjusted logistic regression showed that among cannabis users, other drug use had lower odds of daily cannabis use and could be due to other drug users not considering cannabis as their primary drug. These findings do suggest that interventions regarding reducing cannabis abuse, alcohol abuse, and other drug usage should be integrated.

Those respondents who had multiple diseases or conditions were negatively associated with non-daily cannabis use. Similar results were found among middle-aged and older adults in the United States [12]. This result seems to indicate that cannabis use in this study was more likely used for recreational than medicinal 
Table 2 Simple multinomial regression with cannabis use

\begin{tabular}{|c|c|c|c|c|}
\hline \multirow[t]{2}{*}{ Variable } & \multicolumn{2}{|c|}{ Non-daily cannabis use } & \multicolumn{2}{|c|}{ Almost daily cannabis use } \\
\hline & Crude RRR (95\% Cl) & $P$-value & Crude RRR $(95 \% \mathrm{Cl})$ & $P$-value \\
\hline \multicolumn{5}{|l|}{$\overline{\operatorname{Sex}}$} \\
\hline Female & 1 (Reference) & & 1 (Reference) & \\
\hline Male & $2.52(2.06,3.09)$ & $<0.001$ & $13.35(9.11,19.58)$ & $<0.001$ \\
\hline \multicolumn{5}{|l|}{ Age in years } \\
\hline 45 or more & 1 (Reference) & & 1 (Reference) & \\
\hline $30-44$ & $1.69(1.36,2.09)$ & $<0.001$ & $2.06(1.43,2.96)$ & $<0.001$ \\
\hline $15-29$ & $2.08(1.68,2.57)$ & $<0.001$ & $2.08(1.49,2.91)$ & $<0.001$ \\
\hline \multicolumn{5}{|l|}{ Education } \\
\hline Grade 0-7 & 1 (Reference) & & 1 (Reference) & \\
\hline Grade 8-11 & $1.25(1.01,1.57)$ & 0.042 & $2.60(1.97,3.44)$ & $<0.001$ \\
\hline Grade 12 or more & $1.09(0.89,1.35)$ & 0.404 & $1.36(1.02,1.81)$ & 0.037 \\
\hline \multicolumn{5}{|l|}{ Marital status } \\
\hline Married & 1 (Reference) & & 1 (Reference) & \\
\hline Separated/divorced/widowed & $0.87(0.63,1.22)$ & 0.427 & $0.97(0.47,2.02)$ & 0.944 \\
\hline Never married & $2.12(1.71,2.62)$ & $<0.001$ & $3.05(2.07,4.51)$ & $<0.001$ \\
\hline \multicolumn{5}{|l|}{ Population group } \\
\hline African Black & 1 (Reference) & & 1 (Reference) & \\
\hline White & $0.97(0.71,1.32)$ & 0.836 & $0.50(0.27,0.94)$ & 0.032 \\
\hline Coloured & $1.27(0.97,1.66)$ & 0.086 & $1.54(1.13,2.08)$ & 0.006 \\
\hline Indian or Asian & $0.98(0.95,1.47)$ & 0.913 & $0.42(0.24,0.73)$ & 0.002 \\
\hline \multicolumn{5}{|l|}{ Employement status } \\
\hline Employed/self-employed & 1 (Reference) & & 1 (Reference) & \\
\hline Unemployed & $1.07(0.88,1.29)$ & 0.499 & $0.83(0.63,1.09)$ & 0.170 \\
\hline Not in labour force & $1.11(0.86,1.43)$ & 0.414 & $0.35(0.21,0.57)$ & $<0.001$ \\
\hline \multicolumn{5}{|l|}{ Residence } \\
\hline Rural informal (tribal areas) & 1 (Reference) & & 1 (Reference) & \\
\hline Rural (farms) & $1.12(0.83,1.51)$ & 0.472 & $1.39(0.85,2.29$ & 0.187 \\
\hline Urban & $1.09(0.86,1.37)$ & 0.474 & $1.77(1.22,2.59)$ & 0.003 \\
\hline \multicolumn{5}{|l|}{ Alcohol use disorder } \\
\hline No & 1 (Reference) & & 1 (Reference) & \\
\hline Yes & $3.88(2.68,4.28)$ & $<0.001$ & $5.88(4.54,7.63)$ & $<0.001$ \\
\hline \multicolumn{5}{|l|}{ Other drugs } \\
\hline No & 1 (Reference) & & 1 (Reference) & \\
\hline Yes & $46.89(34.72,63.33)$ & $<0.001$ & $13.96(9.04,21.54)$ & $<0.001$ \\
\hline \multicolumn{5}{|l|}{ Psychological distress } \\
\hline No & 1 (Reference) & & 1 (Reference) & \\
\hline Yes & $1.11(0.86,1.43)$ & 0.412 & $1.22(0.87,1.72)$ & 0.254 \\
\hline \multicolumn{5}{|l|}{ Physical multimorbidity } \\
\hline 0 & 1 (Reference) & & 1 (Reference) & \\
\hline 1 & $0.66(0.53,0.82)$ & $<0.001$ & $0.50(0.33,0.76)$ & $<0.001$ \\
\hline 2 or more & $0.34(0.21,0.53)$ & $<0.001$ & $0.11(0.04,0.33)$ & $<0.001$ \\
\hline \multicolumn{5}{|l|}{ Health care utilization } \\
\hline No & 1 (Reference) & & 1 (Reference) & \\
\hline Yes & $0.72(0.61,0.85)$ & $<0.001$ & $0.52(0.39,0.69)$ & $<0.001$ \\
\hline
\end{tabular}

purposes for multiple chronic conditions. Unlike some previous research $[16,17]$, this survey did not show an association between psychological distress and non-daily or daily cannabis use. In line with previous studies on risky alcohol use $[18,19]$, this study found an association between less frequent primary health care utilization and non-daily and daily cannabis use. It is possible that those with cannabis use more frequently attend hospital or emergency medical services.

\section{Study limitations}

The study was limited by its cross-sectional design and selfreport of data, including cannabis use. The self-report of cannabis use may led to biased responses. Cannabis and other drug use were only assessed with a shortened version of the ASSIST, not allowing us to report on cannabis and other drug use disorders, as well as tobacco use disorders. However, it has been estimated [36] that one-third of almost daily cannabis users would fulfil the criteria of DSM 
Table 3 Multiple multinomial regression with non-daily and daily cannabis use (reference no past 3-month cannabis use)

\begin{tabular}{|c|c|c|c|c|}
\hline \multirow[t]{2}{*}{ Variable } & \multicolumn{2}{|l|}{ Non-daily cannabis use } & \multicolumn{2}{|c|}{ Almost daily cannabis use } \\
\hline & Adjusted RRR (95\% CI) & $P$-value & Adjusted RRR $(95 \% \mathrm{Cl})$ & $P$-value \\
\hline \multicolumn{5}{|l|}{ Sex } \\
\hline Female & 1 (Reference) & & 1 (Reference) & \\
\hline Male & $2.20(1.77,2.75)$ & $<0.001$ & $10.55(6.88,16.18)$ & $<0.001$ \\
\hline \multicolumn{5}{|l|}{ Age in years } \\
\hline 45 or more & 1 (Reference) & & 1 (Reference) & \\
\hline $30-44$ & $1.06(0.81,1.38)$ & 0.665 & $0.92(0.61,1.38)$ & 0.685 \\
\hline $15-29$ & $1.09(0.80,1.49)$ & 0.587 & $0.92(0.60,1.39)$ & 0.677 \\
\hline \multicolumn{5}{|l|}{ Education } \\
\hline Grade $0-7$ & 1 (Reference) & & 1 (Reference) & \\
\hline Grade 8-11 & $1.14(0.88,1.49)$ & 0.322 & $1.75(1.26,2.44)$ & $<0.001$ \\
\hline Grade 12 or more & $1.02(0.76,1.36)$ & 0.899 & $0.99(0.70,1.40)$ & 0.974 \\
\hline \multicolumn{5}{|l|}{ Marital status } \\
\hline Married & 1 (Reference) & & 1 (Reference) & \\
\hline Separated/divorced/widowed & $0.95(0.62,1.45)$ & 0.800 & $1.08(0.51,2.28)$ & 0.843 \\
\hline Never married & $2.05(1.54,2.71)$ & $<0.001$ & $3.00(1.97,4.59)$ & $<0.001$ \\
\hline \multicolumn{5}{|l|}{ Population group } \\
\hline African Black & 1 (Reference) & & 1 (Reference) & \\
\hline White & $1.58(1.06,2.24)$ & 0.024 & $0.88(0.42,1.84)$ & 0.730 \\
\hline Coloured & $1.25(0.90,1.72)$ & 0.189 & $1.52(1.09,2.11)$ & 0.013 \\
\hline Indian or Asian & $1.27(0.76,2.12)$ & 0.368 & $0.59(0.31,1.13)$ & 0.112 \\
\hline \multicolumn{5}{|l|}{ Employement status } \\
\hline Employed/self-employed & 1 (Reference) & & 1 (Reference) & \\
\hline Unemployed & $1.08(0.83,1.39)$ & 0.570 & $0.89(0.64,1.23)$ & 0.470 \\
\hline Not in labour force & $0.97(0.68,1.39)$ & 0.879 & $0.32(0.17,0.61)$ & $<0.001$ \\
\hline \multicolumn{5}{|l|}{ Residence } \\
\hline Rural informal (tribal areas) & 1 (Reference) & & 1 (Reference) & \\
\hline Rural (farms) & $1.00(0.70,1.44)$ & 0.990 & $0.94(0.54,1.64)$ & 0.818 \\
\hline Urban & $1.00(0.77,1.30)$ & 0.983 & $1.45(0.92,2.28)$ & 0.106 \\
\hline \multicolumn{5}{|l|}{ Alcohol use disorder } \\
\hline No & 1 (Reference) & & 1 (Reference) & \\
\hline Yes & $2.89(2.12,3.78)$ & $<0.001$ & $3.07(2.30,4.09)$ & $<0.001$ \\
\hline \multicolumn{5}{|l|}{ Other drugs } \\
\hline No & 1 (Reference) & & 1 (Reference) & \\
\hline Yes & $52.29(36.17,75.68)$ & $<0.001$ & $16.44(9.75,27.72)$ & $<0.001$ \\
\hline \multicolumn{5}{|l|}{ Physical multimorbidity } \\
\hline 0 & 1 (Reference) & & 1 (Reference) & \\
\hline 1 & $0.86(0.64,1.15)$ & 0.311 & $0.87(0.53,1.41)$ & 0.562 \\
\hline 2 or more & $0.47(0.29,0.78)$ & 0.003 & $0.24(0.07,0.79)$ & 0.020 \\
\hline \multicolumn{5}{|l|}{ Health care utilization } \\
\hline No & 1 (Reference) & & 1 (Reference) & \\
\hline Yes & $0.94(0.78,1.13)$ & 0.518 & $0.77(0.56,1.05)$ & 0.099 \\
\hline
\end{tabular}

RRR Relative Risk Ratio, Cl Confidence Interval 
Table 4 Logistic regression with daily cannabis use among active cannabis users $(N=1728)$

\begin{tabular}{|c|c|c|c|c|}
\hline Variable & Crude OR $(95 \% \mathrm{Cl})$ & $P$-value & Adjusted OR $(95 \% \mathrm{Cl})$ & $P$-value \\
\hline \multicolumn{5}{|l|}{$\overline{\operatorname{Sex}}$} \\
\hline Female (23.4\%) & 1 (Reference) & & 1 (Reference) & \\
\hline Male (76.6\%) & $5.29(3.40,8.25)$ & $<0.001$ & $3.88(2.40,6.28)$ & $<0.001$ \\
\hline \multicolumn{5}{|l|}{ Age in years } \\
\hline 45 or more $(18.3 \%)$ & 1 (Reference) & & - & \\
\hline 30-44 (35.1\%) & $1.22(0.80,1.86)$ & 0.351 & & \\
\hline $15-29(46.7 \%)$ & $1.00(0.68,1.47)$ & 0.999 & & \\
\hline \multicolumn{5}{|l|}{ Education } \\
\hline Grade 0-7 (30.9\%) & 1 (Reference) & & 1 (Reference) & \\
\hline Grade 8-11 (34.6\%) & $2.07(1.46,2.94)$ & $<0.001$ & $1.25(0.82,1.99)$ & 0.298 \\
\hline Grade 12 or more (34.5\%) & $1.24(0.86,1.79)$ & 0.248 & $0.90(0.57,1.44)$ & 0.670 \\
\hline \multicolumn{5}{|l|}{ Marital status } \\
\hline Married (16.3\%) & 1 (Reference) & & - & \\
\hline Separated/divorced/widowed (4.4\%) & $1.12(0.50,2.47)$ & 0.788 & & \\
\hline Never married (79.3\%) & $1.44(0.92,2.25)$ & 0.107 & & \\
\hline \multicolumn{5}{|l|}{ Population group } \\
\hline African Black (78.9\%) & 1 (Reference) & & 1 (Reference) & \\
\hline White (7.2\%) & $0.52(0.27,1.00)$ & 0.049 & $0.65(0.32,1.32)$ & 0.236 \\
\hline Coloured (11.6\%) & $1.21(0.83,1.76)$ & 0.310 & $1.12(0.71,1.78)$ & 0.618 \\
\hline Indian or Asian (2.3\%) & $0.43(0.24,0.75)$ & 0.003 & $0.54(0.30,0.99)$ & 0.046 \\
\hline \multicolumn{5}{|l|}{ Employement status } \\
\hline Employed/self-employed (37.2\%) & 1 (Reference) & & 1 (Reference) & \\
\hline Unemployed (50.3\%) & $0.77(0.55,1.09)$ & 0.137 & $0.85(0.57,1.26)$ & 0.421 \\
\hline Not in the labour force (12.5\%) & $0.31(0.18,0.55)$ & $<0.001$ & $0.33(0.16,0.66)$ & 0.002 \\
\hline \multicolumn{5}{|l|}{ Residence } \\
\hline Rural informal (tribal areas) (22.0\%) & 1 (Reference) & & 1 (Reference) & \\
\hline Rural (farms) (5.0\%) & $1.25(0.77,2.04)$ & 0.372 & $0.96(0.55,1.69)$ & 0.892 \\
\hline Urban (73.1\%) & $1.63(1.12,2.38)$ & 0.012 & $1.54(0.98,2.45)$ & 0.068 \\
\hline \multicolumn{5}{|l|}{ Alcohol use disorder } \\
\hline No (71.3\%) & 1 (Reference) & & 1 (Reference) & \\
\hline Yes (28.7\%) & $1.74(1.24,2.43)$ & $<0.001$ & $1.26(0.85,1.85)$ & 0.240 \\
\hline \multicolumn{5}{|l|}{ Other drugs } \\
\hline No $(74.9 \%)$ & 1 (Reference) & & 1 (Reference) & \\
\hline Yes $(25.1 \%)$ & $0.30(0.19,0.47)$ & $<0.001$ & $0.42(0.26,0.66)$ & $<0.001$ \\
\hline \multicolumn{5}{|l|}{ Psychological distress } \\
\hline No $(77.4 \%)$ & 1 (Reference) & & - & \\
\hline Yes $(22.6 \%)$ & $1.10(0.73,1.65)$ & 0.646 & & \\
\hline \multicolumn{5}{|l|}{ Physical multimorbidity } \\
\hline $0(86.1 \%)$ & 1 (Reference) & & - & \\
\hline $1(12.4 \%)$ & $0.76(0.47,1.24)$ & 0.276 & & \\
\hline 2 or more $(1.5 \%)$ & $0.32(0.10,1.06)$ & 0.062 & & \\
\hline \multicolumn{5}{|l|}{ Health care utilization } \\
\hline No $(62.5 \%)$ & 1 (Reference) & & 1 (Reference) & \\
\hline Yes (37.5\%) & $0.72(0.51,1.00)$ & 0.048 & $0.82(0.58,1.17)$ & 0.276 \\
\hline
\end{tabular}

III cannabis dependence. Another study limitation was that there was no control over the Type I error rate with multiple tests. Thus, the chance for a Type I error is larger than 0.05 . Futhermore, the motivation of cannabis use, such as medicinal or recreactional, was not assessed, and should be included in future studies.

\section{Conclusions}

In this large national population-based survey among persons 15 and older in 2017 in South Africa, almost one in ten participants engaged past 3-month cannabis use. Several sociodemographic factors (male sex, never married, having Grade 8-11 education, and Coloureds) and health indicators (alcohol use disorder, other drug use and no physical multimorbidity) were identified that were associated with non-daily and/or daily cannabis use. Among active cannabis users, other drug use had lower odds of daily cannabis use. It is recommended that reasons or motivations for cannabis use be investigated to fully understand its usage and then make informed 
policy recommendations. Given that school going children, Grades 8-11 have now started using cannabis compared to previous years, literature, requires immediate intervention to curb the usage and thus ensure these youth stay in school. Among the Coloured population group, targeted inteventions are required to remedy the injustices of South Africa's Apartheid past. Substance abuse policies need to be integrated to take all substances, including cannabis, alcohol, and illicit drugs, into consideration as this study as well as the literature show that they are interlinked and thus require an overarching integrated intervention with greater emphasis on illicit drug use.

\section{Abbreviations}

ASSIST: Alcohol, Smoking and Substance Involvement Screening Test: AUDIT: Alcohol Use Disorders Identification Test;; DSM: Diagnostic and Statistical Manual of Mental Disorders; K10: Kessler Psychological Distress Scale; SALs: Small area layers

\section{Acknowledgements}

Human Sciences Research Council. South African National HIV Prevalence, HIV Incidence, Behaviour and Communication Survey (SABSSM) 2017: Combined All provinces. [Data set]. SABSSM 2017 Combined. Version 1.0. Pretoria South Africa: Human Sciences Research Council [producer] 2017, Human Sciences Research Council [distributor] 2020. https://doi.org/10.14749/1585345902.

\section{Authors' contributions}

"All authors fulfil the criteria for authorship. S.R., K.P. and S.P. conceived and designed the research, performed statistical analysis, drafted the manuscript and made critical revision of the manuscript for key intellectual content. All authors have read and agreed to the published version of the manuscript."

\section{Funding}

Bill and Melinda Gates Foundation, Centers for Disease Control and PreventionHuman Sciences Research Council, President's Emergency Plan for AIDS Relief (Emergency Plan), South African National AIDS Council, United Nations Children's Fund.

\section{Availability of data and materials}

The dataset used and/or analysed during the current study is available from the.

Human Sciences Research Council [distributor] 2020. https://doi.org/10 14749/1585345902.

\section{Declarations}

\section{Ethics approval and consent to participate}

The Human Sciences Research Council (HSRC) Research Ethics Committee (REC: 4/18/11/15) granted ethical approval for the survey. Approval was also granted by the CDC's Center for Global Health (CGH).

\section{Consent for publication}

Not applicable.

\section{Competing interests}

The authors declare that they have no competing interests.

\section{Author details}

'Department of Human and Social Capabilities, Human Sciences Research Council, Private Bag X41, Pretoria 0001, South Africa. ${ }^{2}$ Department of Research Administration and Development, University of Limpopo, Sovenga 0727, South Africa. ${ }^{3}$ ASEAN Institute for Health Development, Mahidol University, Salaya, Phutthamonthon, Nakhon Pathom 73170, Thailand.
Accepted: 12 March 2021

Published online: 20 March 2021

\section{References}

1. Bhalla A, Thirumalaikolundusubramanian P, Fung J, Cordero-Schmidt G, Soghoian S, Sikka VK, et al. Native medicines and cardiovascular toxicity. In: Ramachandran MS, editor. The heart and toxins. San Diego: Academic Press; 2015. p. 175-202.

2. Whiting PF, Wolff RF, Deshpande S, Di Nisio M, Duffy S, Hernandez AV, et al. Cannabinoids for medical use: a systematic review and meta-analysis. JAMA. 2015;313(24):2456-73. https://doi.org/10.1001/jama.2015.6358.

3. Peltzer K, Ramlagan S. Cannabis use trends in South Africa. S Afr J Psychiatr. 2007:13(4):a33. https://doi.org/10.4102/sajpsychiatry.v13i4.33.

4. Peltzer K, Ramlagan S. Illicit drug use in South Africa: findings from a 2008 national population-based survey. S Afr J Psychiatry. 2010;16(1):8-15.

5. United Nations Office on Drugs and Crime (UNODC) World Drug Report 2018. Vienna: UNODC; 2018. https://www.unodc.org/wdr2018/. Accessed 10 Jan 2021

6. United Nations Office on Drugs and Crime (UNODC) DATAUNODC. Country lists. UNODC, 2020. Available at https://dataunodc.un.org/content/countrylist Accessed 2 Oct 2020

7. Teesson M, Slade T, Swift W, Mills K, Memedovic S, Mewton L, et al. Prevalence, correlates and comorbidity of DSM-IV cannabis use and cannabis use disorders in Australia. Aust N Z J Psychiatry. 2012;46(12):118292. https://doi.org/10.1177/0004867412460591.

8. Peltzer K, Phaswana-Mafuya N. Drug use among youth and adults in a population-based survey in South Africa. S Afr J Psychiatry. 2018;24:1139. https://doi.org/10.4102/sajpsychiatry.v24i0.1139 eCollection 2018.

9. Dada S, Burnhams NH, Erasmus J, Parry C, Bhana A, Timol F, Fourie D. Monitoring alcohol, tobacco and other drug use trends in South Africa: July - December 2016, 2017. Available at www.sahealthinfo.org/admodule/sa cendu.htm Accessed 17 Nov 2020.

10. Dada S, Burnhams NH, Erasmus J, Parry C, Bhana A. Update January 2018 alcohol and other drug use trends: January - June 2017 (phase 42), 2018. Available at www.sahealthinfo.org/admodule/sacendu.htm Accessed 17 Nov 2020

11. Berge J, Håkansson A, Berglund M. Alcohol and drug use in groups of cannabis users: results from a survey on drug use in the Swedish general population. Am J Addict. 2014;23(3):272-9. https://doi.org/10.1111/j.1521-03 91.2014.12097.x

12. Han BH, Palamar JJ. Marijuana use by middle-aged and older adults in the United States, 2015-2016. Drug Alcohol Depend. 2018;191:374-81. https:// doi.org/10.1016/j.drugalcdep.2018.07.006.

13. Callaghan RC, Sanches M, Benny C, Stockwell T, Sherk A, Kish SJ. Who consumes most of the cannabis in Canada? Profiles of cannabis consumption by quantity. Drug Alcohol Depend. 2019;205:107587. https:// doi.org/10.1016/j.drugalcdep.2019.107587.

14. Ogborne AC, Smart RG. Cannabis users in the general Canadian population. Subst Use Misuse. 2000;35(3):301-11. https://doi.org/10.3109/1082608000914 7698

15. Han BH, Ko R, Palamar JJ. Substance use by adults with medical multimorbidity in the United States, 2015-2016. J Gen Intern Med. 2019. 34(8):1394-6. https://doi.org/10.1007/s11606-019-04980-1.

16. Weinberger AH, Pacek LR, Sheffer CE, Budney AJ, Lee J, Goodwin RD. Serious psychological distress and daily cannabis use, 2008 to 2016: potential implications for mental health? Drug Alcohol Depend. 2019;197: 134-40. https://doi.org/10.1016/j.drugalcdep.2019.01.010

17. Votaw VR, McHugh RK, Vowles KE, Witkiewitz K. Patterns of Polysubstance use among adults with tranquilizer misuse. Subst Use Misuse. 2020;55(6) 861-70. https://doi.org/10.1080/10826084.2019.1708118.

18. Miquel L, Manthey J, Rehm J, Vela E, Bustins M, Segura L, et al. Risky alcohol use: the impact on health service use. Eur Addict Res. 2018;24(5):234-44. https://doi.org/10.1159/000493884

19. Jenkins KR, Zucker RA. The prospective relationship between binge drinking and physician visits among older adults. J Aging Health. 2010;22(8):1099113. https://doi.org/10.1177/0898264310376539.

20. Stein DJ. Position statement on cannabis. S Afr Med J. 2016;106(6):45-6. https://doi.org/10.7196/SAMJ.2016.v106i6.10863.

21. Simbayi LC, Zuma K, Zungu N, Moyo S, Marinda E, Jooste S, et al. South African national HIV prevalence, incidence. In: Behaviour and communication survey, vol. 2017. Cape Town: HSRC Press; 2019. 
22. Statistics South Africa. Mid-year population estimates 2017. Pretoria: StatsSA; 2017.

23. Humeniuk RE, Henry-Edwards S, Ali RL, Poznyak V, Monteiro M. The alcohol, smoking and substance involvement screening test (ASSIST): manual for use in primary care. Geneva: World Health Organization; 2010.

24. Babor TF, Higgens-Biddle JC, Saunders JB, Monteiro MG. AUDIT: the alcohol use disorders identification test. In: Guidelines for use in primary care. Geneva: World Health Organization, Department of Mental Health and Substance Dependence; 2001.

25. Peltzer K, Davids A, Njuho P. Alcohol use and problem drinking in South Africa: findings from a national population-based survey. Afr J Psychiatry. 2011;14(1):30-7. https://doi.org/10.4314/ajpsy.v14i1.65466.

26. Liskola J, Haravuori H, Lindberg N, Niemelä S, Karlsson L, Kiviruusu O, Marttunen M. AUDIT and AUDIT-C as screening instruments for alcohol problem use in adolescents. Drug Alcohol Depend. 2018;188:266-73. https://doi.org/10.1016/j.drugalcdep.2018.04.015.

27. Kessler RC, Andrews G, Colpe L, Hiripi E, Mroczek DK, Normand SL, Walters EE, Zaslavsky AM. Short screening scales to monitor population prevalences and trends in non-specific psychological distress. Psychol Med. 2002;32(6): 959-76. https://doi.org/10.1017/s0033291702006074.

28. Peltzer K, Ramlagan S, Johnson BD, Phaswana-Mafuya N. Illicit drug use and treatment in South Africa: a review. Subst Use Misuse. 2010;45(13):2221-43. https://doi.org/10.3109/10826084.2010.481594.

29. Dada S, Burnhams NH, Erasmus J, Parry C, Bhana A, Pretorius S, et al. South African community epidemiology network on drug use (SACENDU) - phase 43, 2018. Available at https://www.samrc.ac.za/sites/default/files/atta chments/2018-11-05/SACENDUFullReportPhase43June2018.pdf Accessed 19 Nov 2020.

30. Fergusson DM, Horwood LJ, Beautrais AL. Cannabis and educational achievement. Addiction. 2003;98(12):1681-92. https://doi.org/10.1111/j.13600443.2003.00573.x

31. Lynskey M, Hall W. The effects of adolescent cannabis use on educational attainment: a review. Addiction. 2000;95(11):1621-30. https://doi.org/10.104 6/j.1360-0443.2000.951116213.x.

32. van Heerden MS, Grimsrud AT, Seedat S, Myer L, Williams DR, Stein DJ. Patterns of substance use in South Africa: results from the south African stress and health study. S Afr Med J. 2009:99(5 Pt 2):358-66.

33. Kalichman SC, Simbayi LC, Jooste S, Cherry C, Cain D. Poverty-related stressors and HIV/AIDS transmission risks in two south African communities. J Urban Health. 2005;82(2):237-49. https://doi.org/10.1093/jurban/jti048.

34. Bartholomew Eldredge LK, Markham CM, Ruiter RAC, Fernandez ME, Kok G, Parcel GS. Planning health promotion programs: an intervention mapping approach. 4th ed. San Francisco: Jossey-Bass; 2016.

35. Teesson M, Farrugia P, Mills K, Hall W, Baillie A. Alcohol, tobacco, and prescription drugs: the relationship with illicit drugs in the treatment of substance users. Subst Use Misuse. 2012;47(8-9):963-71. https://doi.org/1 0.3109/10826084.2012.663283.

36. Kandel DB, Davies M. Progression to regular marijuana involvement: Phenomenology and risk factors for near-daily use. In: Glantz MD, Pickens RW, editors. Vulnerability to drug abuse: American Psychological Association; 1992. p. 211-53. https://doi.org/10.1037/10107-009.

\section{Publisher's Note}

Springer Nature remains neutral with regard to jurisdictional claims in published maps and institutional affiliations.

Ready to submit your research? Choose BMC and benefit from:

- fast, convenient online submission

- thorough peer review by experienced researchers in your field

- rapid publication on acceptance

- support for research data, including large and complex data types

- gold Open Access which fosters wider collaboration and increased citations

- maximum visibility for your research: over $100 \mathrm{M}$ website views per year

At BMC, research is always in progress.

Learn more biomedcentral.com/submissions 